\title{
CONDITTILE ȘI STRATEGIILE UNUI TRANSFER DE CAPITAL CULTURAL: IMPORTUL POEZIEI AMERICANE ÎN OPTZECISMUL ROMÂNESC
}

\author{
Teona Farmatu \\ teonafarmatu@gmail.com \\ Universitatea „Babeș-Bolyai”, Cluj-Napoca
}

\begin{abstract}
Within the frame of theoretical ideas of World Literature methodology, my paper is aiming to reconsider the relationship between the post-war North-American poetry and the Romanian 80s Generation of poets. Being a complex import, this article sheds light on the conditions and the strategies of this phenomenon through a contextual equation which is more important than a strictly textual one. As a major conclusion of this research, the import of North-American poetry forms, models, ideas, as well as of ideological attitudes is the result of the Romanian young authors' emulation regarding this faraway literary model. Therefore, this relationship between a centre and a (semi)periphery does not imply a colonizing model of a major culture's hegemony on a minor one.
\end{abstract}

Key words: 80s Generation, North-American poetry schools, Monday Literary Circle, emulation model, strategies, ideological conditions.

Deși analizele tradiţionale ale textelor literare abordau tangențial și contextul apariţiei acestora, noile metodologii din sfera World Literature prioritizează contextualizările, astfel încât climatul gestației textelor sau al intrării lor pe piața de carte ajunge să constituie un nod esențial în sistematizarea operelor și, mai cu seamă, a influențelor (voluntar sau involuntar preluate) care contribuie la producerea lor. Abordările așa-zis „de la distanță”, panoramice implică predispoziția pentru reconfigurarea contextelor și regândirea raporturilor centru-(semi)periferie dincolo de o eventuală rigiditate a granițelor fizice, lingvistice, ideologice sau geoculturale.

Odată cu mutarea perspectivei dinspre conservarea autonomiei literarului în spațiile naționale înspre cadrele ex-literare și ex-naționale, caracterul evolutiv al formulelor transferate dintr-un spațiu în altul este strâns legat nu atât de natura lor intrinsecă, ci, mai degrabă, de parcursul lor extern și de gradul lor de permeabilitate la un nou context sociocultural și/sau ideologic. Procesualitatea acestor importuri și adaptările lor depind de câteva aspecte care, în genere, perturbă 
dinamicile interne ale literaturilor autohtone și modifică substanțial istoriografia literară indigenă: circulația largă sau, din contră, limitată a textelor în original, statutul prin excelență de mediator al traducerilor, predispoziția sau, dimpotrivă, reticența mediului-țintă(1) faţă de asimilarea lor, anumite specificități provenite din tradiția spațiului autohton, ideologia ambelor culturi aflate în ecuație (cu accentul înspre climatul politic al celei care importă elemente), strategiile prin care sunt apropriate noile forme, precum și metamorfozele inerente ale acestora.

Astfel, aparatul prin care se (re)stabilește contextul în care are loc un transfer de capital cultural (cel mai adesea, dinspre un centru de influență înspre un spațiu marginal) operează cu un instrumentar fluctuant și variat cu scopul relevării și al centralizării unor pregnanțe sau a unor pattern-uri pe care noul spaţiu-gazdă le asimilează. Cert este faptul că, odată cu avântul metodologiilor din câmpul World Lit., raportul dintre consistența importului (formule, teme, atitudini etc.) și dimensiunea externă a acestuia (condițiile transferului, strategiile de exportare și de importare, climatul ideologic și cel estetic etc.) se modifică substanţial, astfel încât cei doi termeni sunt relaționați de pe poziții egalitare, ba chiar cel de-al doilea - natura extrinsecă a importului - tinde să cântărească mai mult în reconfigurarea legăturilor dintre spațiile literare și în localizarea fiecăruia în parte pe „harta mondială a literelor” (Casanova).

Pe de o parte, atenția asupra contextualizărilor dorește să gestioneze sistematic circulația influențelor literare, iar, pe de altă parte, să observe în ce măsură puterea unei culturi/literaturi centrale generează automat dominație asupra unor culturi/literaturi aşa-zis minore sau (semi)periferice, cum este și spațiul românesc. Cu alte cuvinte, dezbaterile cu privire la relevanța contextelor și a (re)contextualizărilor în studiul literaturii repun în discuție miza hegemonică: cum se modifică raporturile dintre spațiile literare, cine pe cine domină, cu atât mai mult în cazul în care interferențele culturale nu sunt rezultatul unei anexări teritoriale sau simbolice (cum este cazul importului poeziei americane în optzecismul românesc)? În ce măsură geografiile literare se sustrag suprapunerii cu sistemele politico-economice(2), dacă interferențele implică state din zone constrânse ideologic?

De altfel, problematizările contextuale angrenează nu numai diferențele și similitudinile structurale de care dispun, fiecare în parte, spațiile literare angajate în transferuri de capital cultural, cât și receptarea lor în cadrul unui ,veritabil internaționalism științific”(3) (Pierre Bourdieu) sau a unei „,internaţionalizări” înţelese drept opusă „termenului neutralizant de globalizare” (Pascale Casanova). Fie că perspectiva este una scientistă (Bourdieu), fie una, mai degrabă, filosofică, 
bazată pe dialectica hegeliană (Casanova), caracterul tranzitoriu și flexibil al influenţelor literare/culturale implică mai multe tipuri de contexte, toate antrenând, în fond, o abordare pluridimensională, și nu una lineară, ierarhizantă(4). O dată, e vorba de contextul originar, național, din care provin elementele, apoi contextul intern al spaţiilor care le importă și, nu mai puțin relevant, contextul istoric mondial, al disputelor politice și al vicistitudinilor socio-culturale, care afectează în maniere distincte mecanismele interne ale spaţiilor naţionale. Abordarea în succesiune a contextelor (în detrimentul suprapunerii lor) și al comparării acestora ar putea chestiona și caracterul impur al influențelor literare.

Odată ce anumite formule, tematici, atitudini (cu încărcătură ideologică sau doar existențială) părăsesc spațiul de origine, dispare și raportul lor intracultural, dispunând de un caracter relativ liber, ex-centric, dobândit prin (re)lecturile „străine”(5), caracter care, se pare, devine obiectul de studiu al internaționalismului. Ruptura acestor elemente exportate de contextul prim le oferă, deopotrivă, o natură asimilabilă, iar spaţiile literare care le importă exercită asupra lor un alt impact în funcție de dinamica lor internă, de gradul de emulație pe care îl au și de scopurile pe care le urmăresc, metabolizând și instrumentalizând aceste influențe. Eterogenitatea unui spațiu literar național provine și din adaptările pe care un import de capital cultural le suferă, ceea ce, pe de o parte, distorsionează generalizările la nivel generaționist și etichetările fixe, iar, pe de altă parte, resuscitează direcții a căror efervescență, în mediul orginar, se estompează. Spre exemplu, ecourile americanilor ajung în spațiul românesc la aproximativ 25-30 de ani de la nașterea și amploarea generaţiei Beat în Statele Unite.

Capitolul de față se va opri concret asupra unui transfer de capital cultural dinspre Școlile de poezie americană (Școala de la New-York și Școala de la San Francisco) înspre spațiul românesc, la sfârșitul anilor '70 - începutul anilor '80, prin așa-numiții optzeciști, tinerii din valurile lunediste, care produc o mutație de paradigmă în câmpul literar autohton sub aparatul opresiv al dictaturii ceaușiste. Eseul va încerca să inventarieze condiţiile și strategiile acestui import, plecând de la o dublă ipoteză: pe de o parte, faptul că sociopoliticul mediului care importă (spațiul românesc) reprezintă un factor stringent în configurarea fenomenului literar din preajma anilor '80, iar, pe de altă parte, faptul că recontextualizarea influențelor americane generează alte conţinuturi indigene. Altfel spus, dimensiunea transnațională a elementelor care circulă dintr-un spațiu-timp în altul constituie și un factor germinativ în câmpul literar care devine gazdă, impuritatea lor, tocmai dobândită prin transfer și adaptare, funcționând drept stimulant în dinamica 
internă a literaturii autohtone. Deși, după cum remarcă Teodora Dumitru, importul american a fost unul mai degrabă de formă poetică decât de conținut ideologic, exclusivitatea formalismului și plierea lui pe niște conținuturi indigene radical diferite ar reduce relaţia celor două spaţii literare la un traseu unilateral, de tipul epigonismului, însă, având în vedere că textul nu circulă fără contextul său(6), nu poate fi ignorat aportul angajat politic al acestor influențe (originea lor se află, totuși, în militantismul mișcărilor contraculturii, antirasiste, antiinstituţionalizării, anticanonului, etc.). Din aceeași perspectivă a cercetătoarei, contribuția sa își concentrează mizele, într-o mare măsură, asupra figurii lui Mircea Cărtărescu, admirator declarat al beatnicilor, dar a cărui utopie capitalistă și consumeristă desfășurată în poeme nu ar trebui preluată drept imuabilă și general-valabilă pentru toți lunediștii. Sincretismul dobândit al formulelor americane, odată ajunse într-un alt context, preferințele individuale ale tinerilor optzeciști și adaptările acestui apanaj într-un spațiu represiv sunt generatoare de noi conținuturi cel puțin din trei motive: pe plan intern, e vorba de criza estetică a neomodernismului românesc (,the expense of the more hermetic, obscurely self-reflexive, and abstract - pure - tone of the 1960s poets, who were associated with French modernism and dismissed as passé", Dumitru 274) și de contextul represiv al ideologiei dictatoriale (de la precaritatea condițiilor de existență în epocă până la întreținerea izolaționismului cultural și a controlului statului asupra oricăror forme, voite sau nu, de fisurare a sistemului), climat care urmărea să uniformizeze și să distorsioneze avântul tinerilor; apoi, pe plan extern, atmosfera Războiului Rece provoacă aderență față de așa-zisul ,,americanism”, aspect pe marginea căruia li s-au adus acuze optzeciștilor prin atacurile din presa ideologizată a vremii (spre exemplu, din revista Săptămâna). Totuși, în paralel cu acest peisaj precar, de natură belicoasă, este de la sine antrenată o dinamică plurifațetată a poeticilor tinerilor opzeciști, care își manifestă „rebeliunea” atât la nivel colectiv, cât și la nivel individual, de unde eterogenitatea discursurilor de care va dispune optzecismul românesc. În sensul acesta, Ion Bogdan Lefter propune o radiografie relativ nuanțată a personalităților poetice ale protagoniștilor, inventariind, în fond, notele distinctive ale temperamentelor lirice(7).

Interesant este că, din punctul de vedere al raporturilor centru-(semi)periferie sau majorminor, pe care metodologiile World Literature mizează în demersurile de modificare a felului de $a$ privi ceea ce e considerat necanonic/minor/marginal, importul american în optzecismul poetic românesc s-a realizat dinspre un centru de influență al epocii (SUA iar, la nivel intern, New-York și San Francisco) și a fost receptat, chiar dacă la nivel local, de un alt centru, spațiul bucureștean, unde, se consideră, s-a dezvoltat postmodernismul autohton. De ce s-a întâmplat astfel? Un răspuns 
ar veni din natura intrinsecă a spațiului central (în cazul acesta, capitala), fie el aflat sub dictatură, dar cultivându-și anumite nișe, prin care se generează, în plan intern, reacțiile (atât câte au existat) și cvasimișcările clandestine de rezistență. Poziția centrală a Bucureștiului din punct de vedere politic, economic, cultural implică și un grad mai mare de efervescență în mediul underground, al cenacliștilor, și nu mai puțin dens, care urmărea să cultive o minimă dezbatere ideatică liberă și o raliere la tendințe extra-europene, lucru care nu s-a întâmplat în alte spații „,periferice” ale țării (clujean, ieșean, nemțean, deși au existat și aici mici grupări de scriitori). Deși Ion Bogdan Lefter identifică drept specific acestei generații stigmatul ei marginal(8) (cel puțin din cauza climatului cultural ,îngust” și al mutației paradigmatice propuse de optzeciști), poziția centrală de care dispune, totuşi, Cenaclul de Luni le conferă tinerilor aderența la importul dinspre Școlile americane de poezie, import care se realizează progresiv și, în plus, stârnește dezbateri inclusiv în rândul cenacliștilor, lucru care demonstrează faptul că fiecare a asimilat, în funcție de structura sa interioară, de preferințele și de formația intelectuale, precum și de natura etică, anumite forme şi/sau atitudini de la poeți americani diferiți. Nu întâmplător cazul Marianei Marin e un laitmotiv al discuțiilor dintre lunediști, discursul poetei nefiind încadrabil în direcția centrală a grupului, cea de pe urma generației Beat (Liviu Georgescu: „Cum s-a întâmplat și cu poezia Marianei Marin, nici eu nu mă încadram neapărat în formulă’), ci în linia poeziei confesive (Lowell, Plath, Sexton), căreia i se interpune dimensiunea etică specifică autoarei autohtone. Nu în ultimul rând, un aspect care se cuvine menționat e faptul că Cenaclul de Luni, dincolo de faptul că fusese înființat și era coordonat de Nicolae Manolescu (figură tutelară(9)), se desfășura în instituții de stat (Casa de Cultură a studenților, Facultatea de Litere a Universității din București). Poziționarea e cu două tăișuri: imitând mai mult sau mai puțin o grupare underground de tip american, cenacliștii întrețin, deși nu aceasta era miza principală, o formă de fisurare a sistemului din interiorul său, strategie care, în cele din urmă, nu e fezabilă.

Pe de altă parte, importul dinspre America a constituit și un indice valoric pentru lunediști în raport cu cei care nu luau parte la Cenaclu, „non-lunediștii”, sau, de pildă, neoexpresioniștii clujeni (Marta Petreu, Ion Mureșan, Aurel Pantea), plasându-i într-un plan secund față de direcțiile pe care le conturau bucureștenii prin discursurile poeților americani. Așadar, deși importul are o structură obișnuită (dinspre o literatură centrală înspre una marginală), boema bucureșteană a lunediștilor devine una hegemonică datorită emulării modelului poetic american și al atitudinilor acestor grupări nonconformiste. 
Din punct de vedere macrostructural, în primul rând, influențele poeziei americane își găsesc originea în centrul politic și de interes artistic al Statelor Unite, ceea ce le conferă complexitate, virulență și militantism. În al doilea rând, adaptarea lor se produce într-un spațiu central și puternic afectat sociopolitic și cultural, unde gradul de emulație al optzeciștilor și complexele recluziunii sunt direct proporționale cu efervescența și explozia generației Beat în mediul originar. Tipul acesta de raport implică, mai mult decât reducerea la o dominație culturală din partea spațiului american, o relație de atașament (opusă asimilării) al tinerilor lunediști față de niște valori pe care și le apropriază pe fondul cauzelor identificate mai sus. Așadar, nu putem vorbi în termenii unei dominații teritoriale și nici măcar simbolice, dat fiind faptul că originea realizărilor/efectelor acestor interferențe cultural-literare se află, de fapt, în climatul autohton, chiar dacă pseudo-underground, iar o perspectivă unilaterală asupra fenomenului în cauză ar anihila relevanța spațiului așa-zis minor/secundar (spațiul românesc) în transferul de capital cultural. Casanova și Damrosch problematizează acest mecanism relațional drept: „o formă specială de dependență, prin care scriitorii pot, în același timp, să fie dominați și să folosească această dominație ca pe un instrument de emancipare și de legitimare"(Casanova 143) sau o modalitate prin care se poate atinge ,gloria” literară prin emulația modelelor străine(10).

Spațiul românesc era dominat ideologic de dictatura ceaușistă (supusă și ea aparatului rusesc), deci în cazul optzeciștilor români, relația este una mai complexă: nu putem lua în calcul o formă de dominație americană, ci, mai degrabă de subminare a celei ceaușiste(11) (bolșevice) prin sensibilitatea atașantă față de poeticile beatnicilor și prin adoptarea formelor, atitudinilor excontinentale, proces care constituia simultan și o formă de rezistență individuală. Fără a se fi dorit neapărat un nucleu subversiv și angajat ideologic, Cenaclul de Luni cultiva, mai mult sau mai puțin conștient, atitudini antisistem: se coagulează după un principiu simpatetic (pe care îl proliferau Ginsberg și Kerouack), favorizează punerea în circulație internă a unor cărți în limba de origine (lunediștii îi citesc, astfel, pe americani în original(12)), stimulează dezbaterile și eclectismul discursurilor lirice, astfel încât, pe lângă aerul cvasiomogen de generație literară, erau cultivate specificitățile fiecărui discurs poetic. De altfel, așa cum anticipam, în 1983, Cenaclul este interzis, semn că acesta constituia un pericol pentru aparatul statal. Problema centrală a închiderii lui pare să fie, conform mărturiilor lui Nicolae Manolescu, ideea de grup: „Oficialitatea nu mai suporta ideea existenței unui grup literar care, dincolo de deosebirile dintre membrii lui, căpătase o coerență și devenise un soi de forță nu numai literară, chiar politică. [...] și de fiecare dată mă izbea atitudinea 
pe care o avea nu față de oamenii din cenaclu sau față de literatura lor, din care nu înțelegea mare lucru, nici n-o interesa foarte mult, ci mereu față de ideea de grup.’'(Lefter, Vlăsie 29)

Metacontextele geoculturale pe care am încercat să le trasez și care repun în discuţie atât dinamica fenomenelor interne din spațiile angajate în transferul de capital cultural/literar, cât și transnaționalismul ecourilor beatnicilor (ataşamentul optzeciștilor și nu simpla dominație a unei literaturi majore; exercitarea influențelor Beat în mai multe state din spațiul est-european: Ungaria, Cehia, Polonia, Estonia) implică și o serie de strategii prin care optzeciștii români își apropriază elementele poeticilor americane și dintre care voi aminti trei: prima, care e întocmai motivul major al interzicerii Cenaclului, și anume coagularea unui grup pe baza unor afinităţi și a unei formații cvasicomune (majoritatea lunediștilor erau absolvenți de filologie sau de filosofie), a doua e reprezentată de afirmarea lor (pentru unii, fiind debutul pe piața literară) prin antologii-manifest (Aer cu diamante și Cinci, iar, mai târziu, Pauză de respirație) și, nu în ultimul rând, „lectura clandestină"(Cordoș 83) ca strategie atât de conservare a libertății individuale, interioare, cât și de formare intelectuală (optzeciștii sunt primii care dobândesc o formație anglo-saxonă, în detrimentul celei franceze dezavuate, „tradiționale”(13) - și, pe alocuri, germane - care dominaseră spațiul cultural român, fenomen fără precedent în literatura autohtonă).

Contextul deconcertant al debutului anilor ' 80 nu ar fi permis afirmarea unor tineri fără vreun background susținut în lipsa unei figuri tutelare, cea a lui Nicolae Manolescu, care își câștigase deja autoritatea în critica literară a momentului și care reușește să coaguleze o grupare studențească. Deși, inițial, cenaclul răspundea unor așteptări inofensive pentru ideologia vremii (lecturi ale membrilor, discuţii aplicate pe texte, dezbateri fără ecouri exterioare etc.), evoluția grupului propune simultan și un sistem intern, o microstructură, prin care tinerii poeți se afirmă pe piața literară, având acum un background drept suport. Cristalizările primului și celui de-al doilea val lunedist se revendică prin cele două antologii cu program estetic: Aer cu diamante (1982) și Cinci (1983), debutul colectiv fiind și o modalitate deopotrivă mai sigură și mai facilă de intrare în mainstream-ul literar, puternic ideologizat al epocii. De asemenea, deși importul propriu-zis ar fi exclusiv formal (poeme ample, aluvionare, prozopoeme, biografism, poezie a confesiunii) la nivel microstructural, optzeciștii împrumută și tipul de configurare a mișcărilor Beat, dat fiind că se coagulaseră într-o boemă bucureșteană, unde, în ciuda climatului precar al României comuniste, a existat o efervescență benefică, cu accente nonconformiste, chiar dacă acestea erau, în foarte mare măsură, reprimate. 
În ceea ce privește „lectura clandestină”, aportul ei este, probabil, cel mai relevant aspect al acestui import literar, întrucât membrii cenaclului reușesc să citească și să pună în circulație, la nivel underground, autori americani în limba de origine (de la T.S. Eliot și Ezra Pound până la John Ashbery, Allen Ginsberg, Frank O'Hara, Sylvia Plath etc. ), ceea ce face ca asimilarea acestor noi discursuri să fie una nemediată lingvistic, aducând odată cu ele caracterul pur al contextelor în care originează valorile, atitudinile, ideologia americanilor și care vor genera efecte distincte în câmpul indigen: de pildă, utopiile capitaliste și consumeriste din poemele cărtăresciene, tonalitatea gravă și angajată etic a Marianei Marin sau realismul retoric, pe alocuri resemnat al lui Traian T. Coșovei, unde ecuația locală frică-frig-foame amprentează discursul. Lectura în limba engleză conservă influențelor un caracter pur, generând o anumită cadență poemelor optzeciștilor, un libertinaj discursiv pe care neomoderniștii îl repudiau. Limba engleză, care, faţă de franceză, este mult mai puțin conservatoare, impune o altă viziune, o altă manieră de percepere a realităților. Optzeciştii români preiau atât formule poetice, cât și o modalitate dezabuzată, aparent nepăsătoare de raportare la, în cazul lor, contextul opresiv al dictaturii ceaușiste.

Reteritorializarea unor aspecte importate din Școlile americane implică și substanțiale adaptări la nivel de atitudine, astfel încât militantismul și extremismul beatnicilor iau forma unei ironice și, uneori, subversive (re)prezentări a realului la optzeciștii români. Pe lângă sarcina „de întreținere și de prezervare a unei vieți interioare” și cea de identificare, „cu rol comunitar terapeutic"(Cordoș 95-96), funcționalitatea lecturii underground proliferează rezistența microsistemului pe care Cenaclul de Luni ajunsese să îl dezvolte.

Așadar, ceea ce Casanova numea, în discuțiile despre metabolizarea atât a unor moșteniri din cultura indigenă, cât și a unor influențe externe, ,,modul în care [autorii] și-au asumat propria libertate"(14), în analiza fenomenului de import ce caracterizează optzecismul poetic autohton, expresia nu e doar o metaforă, având în vedere că, odată formați în spiritul unor poeți americani citiți în original pe cât posibil, tinerii din spațiul românesc își asumă atât o libertate estetică (se rup radical de convenționalismul unor formule neomoderniste), cât și o libertate ideologică, pe care, chiar dacă nu o manifestă, ea poate fi subînțeleasă prin clandestinitatea lecturii și, mai târziu, prin interzicerea definitivă a Cenaclului. Asumarea propriei libertăţi a survenit mai întâi, pe filiera unui import căutat și dorit de tinerii poeți români, apoi pe fundalul politic represiv, cele două coordonate contextuale fiind indisociabile în investigarea acestui transfer inter-continental. Importul de capital cultural dinspre nordul Statelor Unite și adaptările inerente ale elementelor constitutive, odată 
pătrunse în contextul României comuniste, a fisurat spațiul-gazdă, în primul rând, estetic (prin noile forme poetice și noua sensibilitate la real), dar, într-o oarecare măsură, și ideologic, la nivelul unui raport metacontextual și concurențial de microstructură vs. macrostructură. Probabil, dacă influențele americane nu ar fi derivat dintr-un climat militant, nonconformist și disruptiv, nu ar fi fost asimilate atât de impulsiv de către tinerii optzeciști și nici nu ar fi produs o atare contestare și încercare de anihilare a grupului lunedist din partea ideologiei ceaușiste. De altfel, nici în absenţa constrângerii politice și estetice din spațiul autohton, nu s-ar fi stârnit un amplu și fidel ataşament față de literatura americană. Altfel spus, acest import de capital cultural are la bază o relaţie contextuală, care primează înaintea celei rigide, de subordonare culturală.

\section{Note bibliografice:}

1. după modelul: „la langue source - la langue cible”, Pascale Casanova, „Consécration et accumulation de capital littéraire. La traduction comme échange inégal", în Actes de la recherche en sciences sociales, vol. 144, septembrie 2002, pp. 7-20.

2. Teodora Dumitru problematizează ideile din sfera World-system theories, fiind sceptică la adresa independenței geografiilor literare față de sistemul hegemonic al mecanismelor politicoeconomice, ceea ce presupune, în mod fals, că o cultură aflată sub dictatură ar putea fi privită similar cu o cultură dezvoltată într-un mediu democratic: „They have led many to conclude that the geographies of literary-artistic and political-economic hegemonies do not overlap as a matter of course, and that, by the same token, the taxonomies and laws of the capitalist world, as well as what defines that world qua system - the so-called "division of labor" — neither reflect nor coincide with the intricate-makeup and problematics of fiction, poetry or, drama.”, „Gaming the World-System: Creativity, Politics, and Beat Influence in the Poetry of the 1980s Generation", în Mircea Martin, Christian Moraru, Andrei Terian (coord.), Romanian Literature as World Literature, New York-London, Bloomsbury Publishing, 2018, p. 271.

3. „Tout cela me fait penser que l'instauration d'un véritable internationalisme scientifique, qui, à mes yeux, est le début d'un internationalisme tout court, ne peut pas se faire toute seule.", Pierre Bourdieu, „Les conditions sociales de la circulation internationale des idées”, în Actes de la recherche en sciences sociales, vol. 145, decembrie 2002, pp. 3-8.

4. „Nu este vorba despre o simplă opoziție între spațiile literare dominante și cele dominate, ci, mai degrabă, de un continuum: opozițiile, concurența, formele de dominație multiple nu admit o ierarhie de tip linear. În mod evident, nu toți dominații literar se află în aceeași situație.”, Pascale Casanova, Republica mondială a literelor, trad. de Cristina Bîzu, București, Art, 1999, p. 104.

5. „par exemple du fait que quelqu'un qui est une autorité dans son pays n'emporte pas son autorité avec lui, la lecture étrangère peut parfois avoir une liberté que n'a pas la lecture nationale, 
soumise à des effets d'imposition symbolique, de domination ou même de contrainte.", Pierre Bourdieu, Art.cit.

6. „Le fait que les textes circulent sans leur contexte, qu'ils n'emportent pas avec eux le champ de production - pour employer mon jargon - dont ils sont le produit et que les récepteurs, étant euxmêmes insérés dans un champ de production différent, les réinterprètent en fonction de la structure du champ de réception, est générateur de formidables malentendus.", Ibidem.

7. „Mi se pare de altfel că varietatea e un punct esențial în evoluția noii « promoții ». Se simte pregnant aerul unitar al universurilor poetice propuse, avem însă de a face cu o unitate în diversitate.”, Ion Bogdan Lefter, „Spirit critic și personalitate”, în Gheorghe Crăciun (coord.), Competiția continuă. Generația 80 în texte teoretice, Pitești, Editura Paralela 45, 1999 , p. 63.

8. „Cred că statutul, destinul acesta marginal ne era impus din cel puțin două motive. Unul ținând de viața culturală a momentului, care era foarte îngustă, bine îngrădită și a continuat să fie îngrădită până la căderea dictaturii [...]. Celălalt motiv care ne predestina existența marginală interferează într-o măsură cu primul, pornește însă în primul rând de la metabolismul intern al literaturii noastre. Noi am propus o schimbare de paradigmă mare și am întâmpinat în chip firesc dificultăți în recunoașterea acestei literaturi, chiar în interiorul câmpului cultural, în interiorul lumii scriitoricești.", în Ion Bogdan Lefter, Călin Vlasie (coord.), Cenaclul de Luni - 40, București, Cartea Românească, 2017, p. 28.

9. vezi Ioana Macrea-Toma, Privighilenția. Instituții literare în comunismul românesc, ClujNapoca, Casa Cărții de Știință, 2009, p. 78.

10. „The writer from a marginal culture is in a double bind. With little to go on at home, a young writer can only achieve greatness by emulating desirable foreign models", David Damrosch, What is World Literature? New Jersey, Princeton University Press, 2003, pp. 9-10.

11. "More to the point, I suggest that the rising writers of Romania's las Communist decade " import " poetic models from the United States, one of the time's world centers, to articulate a 'double discourse' that, on the one hand, reworks, relocates peripherally, and ultimately decenters symbolically this center itself and, on the other, critiques the Soviet world subsystem of which Communist Romania had been part.”, Teodora Dumitru, Art. cit., p. 272.

12. „Acolo am aflat despre Beat Generation din poezia americană, acolo am împrumutat și am citit cărți în engleză care circulau pe sub mână, acolo am avut parte de primele dezbateri, fricțiuni și bătălii literare.”, Magda Cârneci în Ion Bogdan Lefter, Călin Vlasie (coord.), Cenaclul de Luni 40, Ed.cit., p. 82.

13. „Este pentru prima dată în cultura română când o generație întreagă respinge influența tradițională a culturilor europene (franceză și germană) pentru a se îndrepta spre cea cu totul diferită a Statelor Unite.”, Mircea Cărtărescu, Postmodernismul românesc, București, Humanitas, 1999, p. 152.

14. „,nu vom putea înțelege traiectoria scriitorilor și nici proiectul lor literar, calea urmată pentru a deveni ceea ce sunt, decât pornind de la modul în care și-au asumat propria libertate, perpetuând, 
transformând, refuzând, sporind, uitând sau trădându-și moștenirea literară (și lingvistică) națională.”, Pascale Casanova, Op.cit., p. 55.

\section{Bibliografie:}

***, Cenaclul de Luni - 40, ediție îngrijită de Ion Bogdan Lefter și Călin Vlasie, București, Cartea Românească, 2017.

BOURDIEU, Pierre, „Les conditions sociales de la circulation internationale des idées”, în Actes de la recherche en sciences sociales, vol. 145, decembrie 2002, pp. 3-8.

CĂRTĂRESCU, Mircea, Postmodernismul românesc, București, Humanitas, 1999.

CASANOVA, Pascale, "Consécration et accumulation de capital littéraire. La traduction comme échange inégal", în Actes de la recherche en sciences sociales, vol. 144, septembrie 2002, pp. 7-20.

CASANOVA, Pascale, Republica mondială a literelor, trad. din franceză de Cristina Bîzu, București, Art, 2016.

CORDOȘ, Sanda, Lumi din cuvinte. Reprezentări și identități în literatura română postbelică, București, Cartea Românească, 2012.

CRĂCIUN, Gheorghe (editor), Competiția continuă. Generația 80 în texte teoretice, Pitești, Editura Paralela 45, 1999.

DAMROSCH, David, What is World Literature?, New Jersey, Princeton University Press, 2003.

MACREA-TOMA, Ioana, Privighilenția. Instituții literare în comunismul românesc, Cluj-Napoca, Casa Cărții de Știință, 2009.

MARTIN, Mircea, MORARU, Christian, TERIAN, Andrei (coord.), Romanian Literature as World Literature, New York-London, Bloomsbury Publishing, 2018 